\title{
Implementing a Safe Travelling Technique to Avoid the Collision of Animals and Vehicles in Saudi Arabia
}

\author{
Amr Mohsen Jadi \\ Collage of Computer Science and Engineering \\ University of Ha'il, Ha'il, Saudi Arabia
}

\begin{abstract}
In this work, a safe travelling technique was proposed and implemented a LoRa based application to avoid the collision of animals with vehicles on the highways of Saudi Arabia. For the last few decades, it has been a great challenge for the authorities to secure the life of animals and human being on the roads due to the sudden passage of animals on the highways. In such situations, drivers are not aware of the animal movement, and serious damage is observed with the life of both humans and animals. A LoRaWAN based architecture with a variety of advantages towards low cost and high accuracy of finding the movement of animals is possible with the proposed method and could deliver good results as well. The accuracy of this method was improved to a maximum extent as compared to the existing system due to the usage of LoRa sensors implanted in the animal's skin to trace with the nodes and base stations easily.
\end{abstract}

Keywords-LoRa; Sensor-based mobile applications; runtime monitoring; tracking; global positioning system

\section{INTRODUCTION}

The Middle East is facing a serious problem with the presence of camels on the roads/highways and is the reason for many accidents with an average of about 600-700 deaths in a year. Presence of the stray animals is not only the problem of the Middle East but also found to be a major concern in world-wide countries. In daylight somehow the people are still managing to escape, but in night times it is always a challenging risk to address carefully to save the animal-human life's and avoids the major damages. In this context, a lot of research was carried out by different authors to find reasonable solutions. In the early 70's, Al-Ghamdi highlighted the 30 times rise in road accidents in the Kingdom of Saudi Arabia (KSA) [1]. Later in 80's, it was reported by Tamimi et al., that most of the accidents are due to driver errors (around $90 \%$ ) and they are between the ages of 20 and 40 [2]. Later, Qayed reported a huge number of accidents (around 6,117) in Saudi Arabia from June 1994 to 1995 and among which 2,551 people got injuries and 151 lost their lives [3]. The author in his work explained that due to vehicle collision with other vehicle and fixed objects is mostly seen. However, the collision of vehicles with animals in the night times proved to be a critical issue to be considered carefully on the highways. In a statistical analysis carried out by Ansari et al. revealed that 564,762 people (which is equivalent of $3.5 \%$ of the total population in KSA) were died or injured in road accidents [4]. Later, the government of KSA carried out stringent action against the rash driving citizens and even penalized for any kind of death or injuries caused to the animals. However, this was misused by some of the camel owners to earn money by pushing their animals on roads as reported by Ansari et al. [5]. This has become a serious issue for the governments and the commuters to overcome as it is created the problem. Similar problems of a motor vehicle collision with Kangaroo's were reported in Australia in the night times by Abu-Zidan [6]. Surprisingly the rate of accidents in winter due to the kangaroo-vehicle collision was reported to be very low in Australia. The vehicle collisions with the larger animals generally cause severe trauma to occupants due to fatal attacks caused by the wildlife animals [7]. Therefore, to address these kinds of animal-vehicle collision (AVC) or camel-vehicle collision (CVC) problems various countermeasures have been introduced in the past by many researchers with the help of the government in Saudi Arabia [8]. Similarly, Bashir and AbuZidan proposed different types of preventing techniques to avoid motor vehicle collision (MVC) with large animals [9]. This includes alarming signs, underpasses or overpasses for animals, frightening reflectors, etc.

A lot of data was collected by Huijser to study different types of reasons for AVC revealed that sex and age of the animals are also playing a vital role in the AVC. Sometimes the animals become more protective and aggressive to save their family or even to entertain themselves [10]. Later, Huijser and Kociolek presented a detailed summary with the highlights related to issues, problems, and experiences of different operations such as false positives, false negatives, maintenance, etc. [11]. It was also noted that most of the accidents found to be with the vehicle speeds of above 88 $\mathrm{km} / \mathrm{h}(55 \mathrm{mi} / \mathrm{h})$ and proposed to alert the drivers to reduce speed with a distance of almost $21 \mathrm{~m}(68 \mathrm{ft})$. A lot of research has been carried out in this work towards wildlife-vehicle collision (WVC) and provided different types of mitigation measures to prevent accidents due to animals. The author also discussed different types of animal detection systems and wildlife crossing structures that influence towards reducing the number of accidents in his work [12]. Similar work was carried out by Al-Shimemeri and Arabi on Arabian camels and highlighted the types of injuries that occur due to the collision with the Arabian camels with a weight of over 726 $\mathrm{kg}$ [13]. Many camels tend to sit and relax on the highways in the night times and are killed by accident or by some of the ruthless drivers as shown in Fig. 1. 


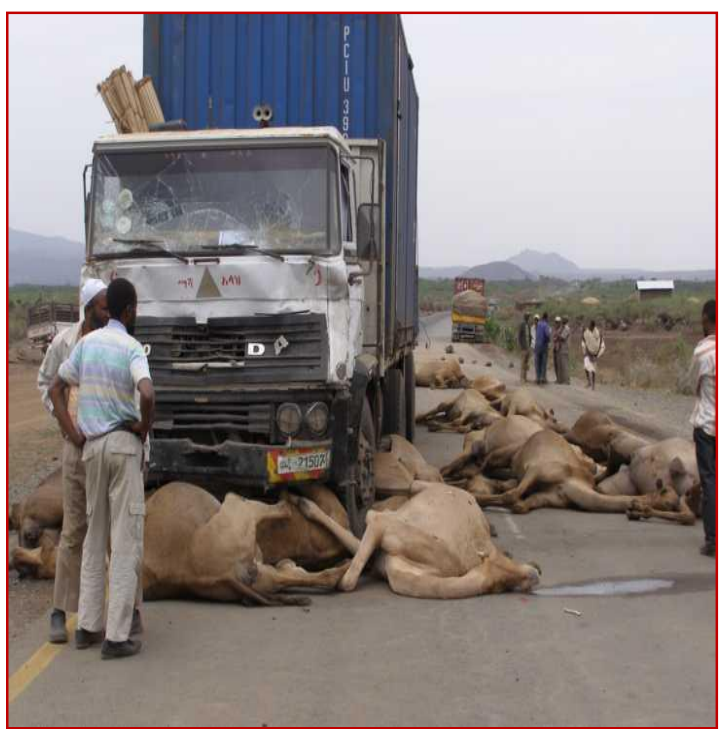

Fig. 1. Shows the Huge loss of Camels due to Accidents with Vehicles on the Highways/Roads.

Global positioning system (GPA) based intelligent CamelVehicle Accident Avoidance system (CVAAS) was introduced by Zahrani et al. for the practical usage on the roads/highways of Saudi Arabia [14]. This work was simulated by following the European Telecommunications Standard Institute (ETSI) frequency allocation of frequency between 5875 to $5905 \mathrm{MHz}$ [15]. This system helps to detect the position of the camels, their movement and direction on their travelling. Based on these parameters a warning will be given to the drivers on the roads/highways. They classified the roads/highways into zones with respect to the distance of the camel's movement and accordingly the alarm system will be changing to alert the commuters. The authors claim to help the SA government to saving billions of Saudi Riyals. In recent times, the KSA is considered to be a developed nation with respect to the infrastructure, roads, and network availability [16]. In such circumstances, the role of mobile phones along with the GPS may help most of the commuters to avoid the accidents due to the collision of vehicles and camels in SA, since KSA tops the world for having the maximum number of mobile phone users [17]. The usage of phosphorous bands in the necks and bodies of the camels initiated by the Oman officials proved to be a bit an effective approach to some extent [18]. However, the drivers with very high speed tend to face the same challenges with these camels with phosphorous bands as well. Some of the challenges due to the camels are shown in Fig. 2.

Now it is reported statistically that SA is spending 13 billion Saudi Riyals annually to treat road-traffic related accidents according to DeNicola et al. [19]. The biggest concern for the SA government is towards the projected growth in road accidents due to animals crossing the roads is going to be more than the present conditions. Recently, it is observed that AVCs have been reduced to some extent by installing the animal crossing warning signboards on the highways and most of the drivers are being trained to get accustomed to the W11-3 and W11-4 signs [20]. Hosseini et al. suggested three important areas to be sorted out for the
AVC problems: a) camel identification problem, b) irresponsible sailors, and c) unidentified camels by the drivers on the roads/highways. The camel owners can be active members in solving these issues to some extent by taking some of the precautionary steps as suggested in the past by some of the authors by providing phosphorous neck bands, body bands, etc. However, the loose animals (especially loose camels) are going to be a big threat to the commuters and these things needed to be addressed carefully.

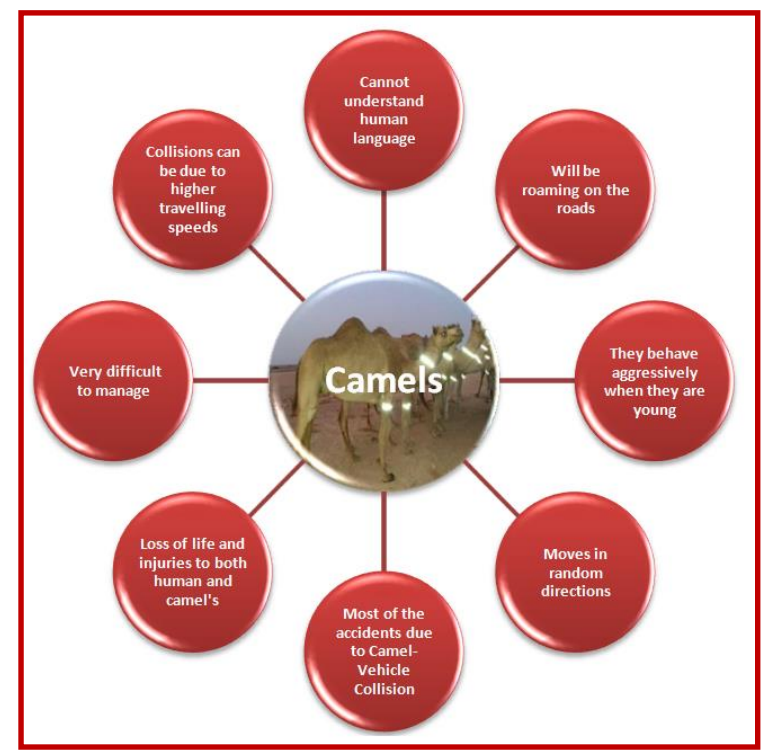

Fig. 2. Shows the different Challenges due to Camels in the Deserts that Cross the Roads/Highways.

In this paper, Section II explores the existence methods and different types of AVC. It tries to explain different types of methods and technologies used for avoiding the collision. Section III explains the proposed architecture and the internal components involved with their role to obtain the desired results to avoid the collision of animals and vehicles. Section IV deals with the functioning of the architecture and implementation methods are discussed in detail, followed by the last section to conclude the overall work carried out in this paper.

\section{Existing Methods to Avoid the Animal Vehicle COLLISION (AVC)}

There are so many ways already introduced to avoid the animal-vehicle collision (AVC) based on a) road-based technologies, b) animal-based technologies, and c) vehiclebased technologies [15]. All these technologies try to minimize the collisions on the roads and aimed to save human and animal lives. The classification of these technologies can be seen in Fig. 3, where some of the latest technologies are introduced as compared with the work of Ragab [15]. Only GPS was introduced in Ragab's work in the category of vehicle-based technology. However, few more technologies are introduced in this paper such as mobile technology based on code division multiple access (CDMA)/orthogonal frequency division multiple access (OFDMA), and sensorbased mobile technology and LoRa (long range) wireless radio frequency (RF) technology. 


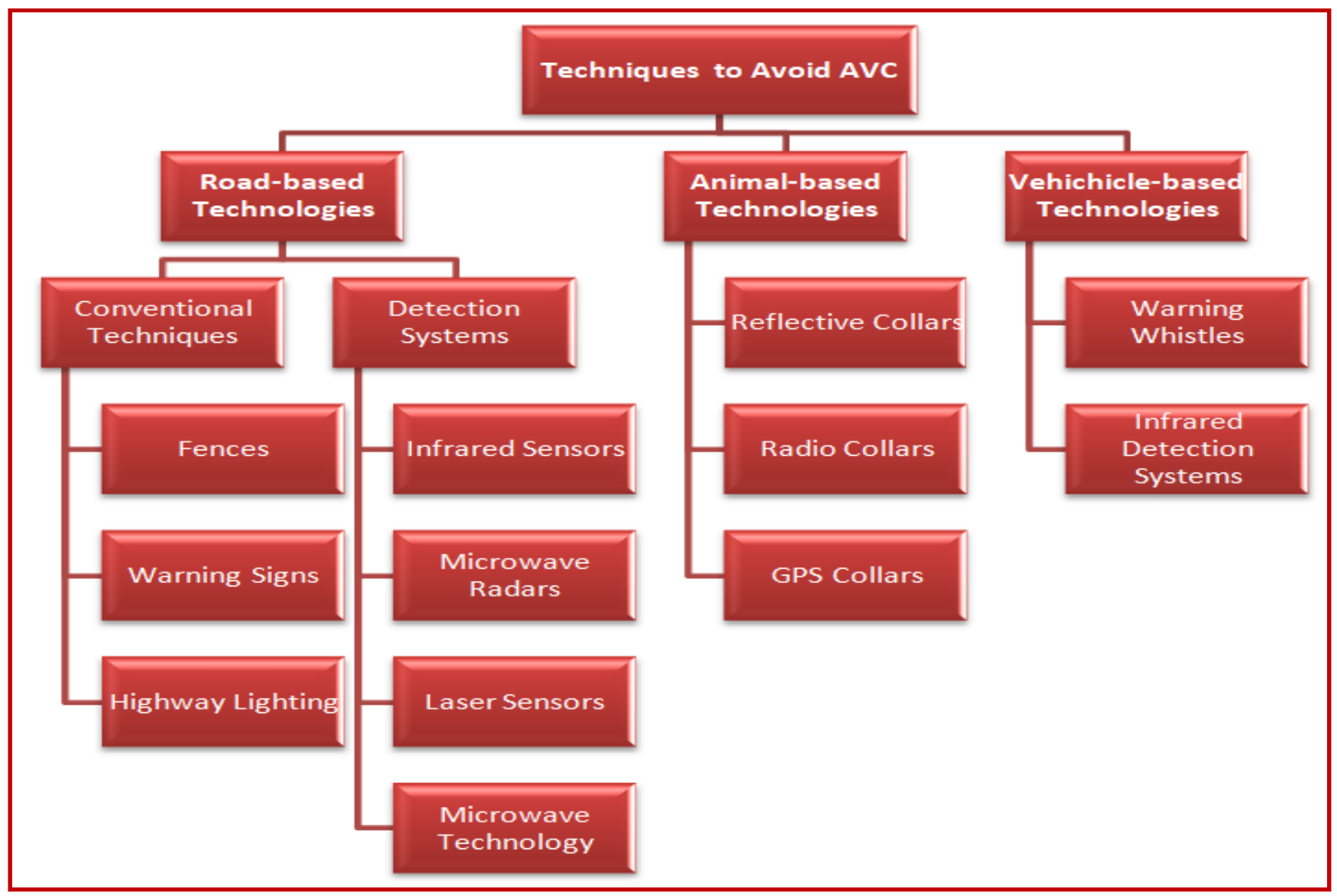

Fig. 3. Shows different Types of Techniques to Avoid AVC on the Roads/Highways.

\section{A. Road-based Technologies}

The road based techniques are classified into two categories as a) conventional techniques and b) detection systems.

- Conventional Techniques: To avoid collision between animals and vehicles, the fences are used to avoid the passage of animals through the roads/highways. The height of the fence must be at least $2 \mathrm{~m}$ to avoid any kind of jumping [21]. However, this method needs regular maintenance and checkups to avoid any kind of exploit breaks with the massive groups of animals hitting the fencing arrangements. At some places, warning signs are installed to inform the commuters about the frequency of animal movement with different types of signals/indicators/direct short message on the signboards. This method helps the commuters to slow the vehicle speed and pass the roads carefully with more attention [15]. Finally, the highway lighting is used from sunset to sunrise for easy passage of the commuters with clear visibility and proper roadside instructions at various junctions about the level of seriousness with the moving animals on the roads/highways along with the signboards [22].

- Detection Systems: There are many methods to detect the animals passing through the roads using sensing devices and technology-based devices/equipment.
There are special categories of vehicle detection systems available in the market, which only identifies the vehicles based on the specifications loaded into their database [23]. These systems cannot detect animals. In such cases, the animals are alerted with the help of long-range audio and visual signals from the designated locations on the roads/highways. In this method, the probability of animals ignoring the caution signals may be noticed.

In the other cases, the infrared sensors are used to identify the animals within a range of $30-100 \mathrm{~m}$ radius on the roads will be installed, so that on the animal detection some kind of signals are being activated to alert the drivers about the animal movement on the roads [15]. The possibility of false detection in this system is more due to broken sensors, loss of power due to improper functioning of solar panels, broken lamps, etc. due to heavy winds and fog during the nighttime with heavy cold environments. Similarly, microwave radar sensors are installed at some locations to identify the movement of larger animals up to $50 \mathrm{~m}$ at a distance with $60^{\circ}$ horizontal angles. Symbols of animals with LED displays are turned ON when the identification of animals will take place [15]. The possibility of false detection during the winter is more due to heavy snow and fog at some of the cold places.

Apart from the above two methods, laser sensors also installed at some locations of Washington, USA, with a pair of lasers installed on both sides of the roads/highways. Whenever 
a rectangle shaped vehicle passes the alert will not be given but when the shape of the animal (non-rectangle) is identified means an alert will be given to the drivers with the help of broken lights. However, in this method, if a deer stands between the laser beams for a longer time (more than a minute) means the warning signals will be turned OFF. The biggest drawback of this method is to use only for the shortest distance and requires high maintenance cost. Finally, microwave technology using a series of transmitters and receivers animal detection is possible using continuous microwave RF signals [27]. Using these method animals are alerted when a vehicle is detected passing through the road by using the variety of noise or light signals. But this system is not useful for high vehicle density roads because the noise will be ringing continuously with the passage of the vehicles [15].

\section{B. Animal-based Technologies}

Different types of collars are introduced in this method to mitigate the AVC by providing a blinking signal system. They are specially classified into two types: a) reflective collars and b) radio collars. These two collars require a minimum infrastructure requirement and are easily available in the market. However, based on the GPS systems also the collars were installed on the animal's neck or at other body parts. These systems can cover a long range of distance and a massive range of animals can be covered using this system [15].

- Reflective Collars: There are many methods to detect the animals passing through the roads using sensing devices and technology-based devices/equipment. There are special categories of vehicle detection systems available in the market, which help the drivers to identify the animals from a long distance due to the reflective tape on the neck of animals. But these collars need to be maintained properly by the owners of the animals so that they are visible from distance and avoidance of collision is sometimes not possible if the distance is very high [28].

- Radio Collars: The first time they were introduced in the year 1999 in Olympic Peninsula, Washington. The animals were radio-collared and the receivers used to scan the frequencies of different radio collars for the whole day. In the presence of a signal at a particular radio-collar within a distance of $400 \mathrm{~m}$ of the roadside, a signal activates the flashing beacons. However, due to the operation of these radio collars is for $24 / 7$, the batteries run out after several years and must be replaced, which is a serious concern using these radio collars [15].

- GPS Collars: Movement of a large number of animals can be traced out by this method and can be helpful in collecting a massive amount of the data to analyze the tendency of the animal movement in different scenarios and meteorological conditions.

\section{Vehicle-based Technologies}

In the early stages, the technology was used in two ways to avoid AVC by using: a) the warning whistles, and b) the inbuilt infrared detection system.
- Warning Whistles: They are independent of any kind of installations, such as the roadside equipment, etc. This concept was introduced in the late 70's [24]. The warning whistles are of air activated type and will be mounted on the front side of the vehicles. These whistles produce ultrasonic frequency waves for any kind of wind rushing towards them. The sounds made by these whistles scare away the animals and the animals are supposed to run away from the roadside. But it is reported that the audio signals will make any effect on the behaviour of the animals [10].

- Infrared Detection System (IDS): In this case, the drivers are alerted with the help of infrared sensors connected to the vehicle when the animals are identified within a range of distances. However, the range of these sensors must be within the reach of animals and must be sufficient enough to allow the drivers to apply the brakes within the time [25]. In this method, a monochromatic display will be used to see the hot objects in white colour and cold objects as black in the images. This method helped the drivers to some extent but some people reported to have headaches. Apart from these, there are many maintenance and technical problems while using IDS. Also, false positive and false negative problems as discussed earlier are common to find by using this method [26].

\section{PRoposed ARCHITECTURE}

At present few countries have got their own GPS satellites includes the US, Russia, European Countries, China and India. Therefore it will be a great deal to adopt the GPS systems in its direct form as a complete solution to resolve the problem in Saudi Arabia due to a huge investment. Therefore in this work, a LoRa based approach is proposed to deal with the collision between animals and vehicles in the proposed system with the help of GPS based Google Maps and sensor-based mobile technology to initiate the alerts.

In the recent times, there are so many advanced technologies evolved into the market that is very much suitable to use for implementing the safe travelling methods for the commuters in Saudi Arabia by avoiding the collision with animals. There are seven technologies in the market that are helpful to track the location. They are Beacons, Wi-Fi, Radio-Frequency Identification (RFID), Near-Field Communication (NFC), Quick Response Codes (QR), LoRa and GPS as listed in Table I with different technological parameters. The range, cost, accuracy, and security of these technologies play a key role to define the type of application where they can be implemented with low risk. There is nothing like a winner or a loser for the tracking game out of all the following tracking technologies [29]. In recent times, the accuracy of GPS proved to be increasing and Bluetooth beacons are well equipped to transfer the larger data. Above and all the usage of mobile phones increased drastically with the increased competition between mobile manufacturers. Most of these technologies proved to be excellent for tracking the people in indoor locations. 


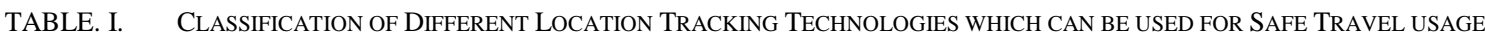

\begin{tabular}{|c|c|c|c|c|c|c|}
\hline Technology & Symbol & Range & Cost & Accuracy & Accessibility & Security \\
\hline Bluetooth Beacon & & $1 \mathrm{~m}-100 \mathrm{~m}$ & $\begin{array}{l}\star \star \star \star \star \\
\text { (2) }\end{array}$ & $\begin{array}{l}\star \star \star \star \star \\
\text { (3) }\end{array}$ & $\begin{array}{l}\star \star \star \star \star \\
\text { (4) }\end{array}$ & $\begin{array}{l}\star \star \star \star \star \\
\text { (3) }\end{array}$ \\
\hline Wi-Fi & & $20 \mathrm{~cm}-100 \mathrm{~m}$ & $\begin{array}{l}\star \star \star \star \star \\
\text { (3) }\end{array}$ & $\begin{array}{l}\star \star \star \star \star \\
\text { (3) }\end{array}$ & $\begin{array}{l}\star \star \star \star \star \\
\text { (3) }\end{array}$ & $\begin{array}{l}\star \star \star \star \star \\
\text { (2) }\end{array}$ \\
\hline RFID & & $1 \mathrm{~cm}-100 \mathrm{~m}$ & $\begin{array}{l}\star \star \star \star \star \\
\text { (4) }\end{array}$ & $\begin{array}{l}\star \star \star \star \star \\
\text { (4) }\end{array}$ & $\begin{array}{l}\star \star \star \star \star \\
\text { (2) }\end{array}$ & $\begin{array}{l}\star \star \star \star \star \\
\text { (4) }\end{array}$ \\
\hline QR Code & & $10 \mathrm{~cm}$ or less & $\begin{array}{l}\star \star \star \star \star \\
\text { (2) }\end{array}$ & $\begin{array}{l}\star \star \star \star \star \\
(5)\end{array}$ & $\begin{array}{l}\star \star \star \star \star \\
(4.5)\end{array}$ & $\begin{array}{l}\star \star \star \star \star \\
\text { (3) }\end{array}$ \\
\hline NFC & & $30 \mathrm{~cm}$ or less & $\begin{array}{l}\star \star \star \star \star \\
\text { (1) }\end{array}$ & $\begin{array}{l}\star \star \star \star \star \\
(5)\end{array}$ & $\begin{array}{l}\star \star \star \star \star \\
\text { (3) }\end{array}$ & $\begin{array}{l}\star \star \star \star \star \\
(4.5)\end{array}$ \\
\hline LORA & & $45 \mathrm{~km}$ or more & $\begin{array}{l}\star \star \star \star \star \\
\text { (1) }\end{array}$ & $\begin{array}{l}\star \star \star \star \star \\
\text { (1) }\end{array}$ & $\begin{array}{l}\star \star \star \star \star \\
\text { (1) }\end{array}$ & $\begin{array}{l}\star \star \star \star \star \\
\text { (1) }\end{array}$ \\
\hline GPS & & Unlimited & $\begin{array}{l}\star \star \star \star \star \\
\text { (1) }\end{array}$ & $\begin{array}{l}\star \star \star \star \star \\
\text { (2) }\end{array}$ & $\begin{array}{l}\star \star \star \star \star \\
(4.5)\end{array}$ & $\begin{array}{l}\star \star \star \star \star \\
\text { (3) }\end{array}$ \\
\hline
\end{tabular}

Even till date, GPS is the most useful tracking technology as compared to others available in the market. The basic advantage of GPS is that they can be installed in smartphones and even on basic phones as well. Due to the unlimited range of GPS, it is always the best method to use along with mobile phones. Whereas in the case of Bluetooth, the upgraded Bluetooth 5 helped most of the mobile manufacturers to increase the range 4 times, speed by 8 times and enhanced the broadcast message capacity, but it cannot be used for any kind of animal tracking due to the range. Similarly, RFID, QR Code, and NFC are a bit more accurate but cannot be used due to the low range [29]. Now there is some scope by using the LORA technology due to its range and flexibility to install far locations easily with low power requirements and long battery durability. A detailed explanation of the proposed architecture based on four major technologies involved in this work is explained. The four technologies include: a) Microchip Implantations, b) GPS Based Technology, c) Sensor-Based Mobile Technology, and d) LoRa Wireless RF Technology.

a) Implantations: In recent times, most of the animals are implanted with microchips under the skin of the animals to track their pets. These microchips are very much capable of working for more than 25 years and these chips can be scanned by using the universal scanners produced by the microchip companies. These implants are used with RFID technology with a broad spectrum of frequencies, interfaces, devices, and protocols [30]. The usage of RFID tagging helped to track the animals successfully in the groups [31]. A tracking device suggested by Movers provides a microchip transmitter encapsulated in biological inert material [32]. The major disadvantage of this method is the range and accuracy of the tracking system when the animals are in masses. In the proposed architecture (as shown in Fig. 4), the animals (in case of SA the camels will be focused) will be implanted with LoRa equipped sensors with possible care using the cylinder like small microchips of bio-safe epoxy resin [30]. These chips are field powered and do not require any kind of power sources. b) GPS Based Technologies: The GPS systems are used to track the position of a particular entity by installing a device in any kind of vehicle, cell phone, or special devices that are made for a special purpose. These systems use the global navigation satellite systems (GNSS) networks, which incorporate the range of satellites using microwave signals which are transmitted to the GPS devices giving the information of the location [33]. Now in the present problem scenario, the animals can be tagged with some kind of GPS collars in their neck or body to observe the movement of animals remotely and communicated the same with the help of mobile based applications. This system can be very much useful to access the location, speed of the animal movement, time and direction as well. The biggest advantage of this system is that it can cover longer ranges with minimum effort as compared to any other system. In the proposed technique, the GPS based Google Maps platform will be integrated with the newly developed application to get the information of animal movement on the screen of the mobile phones, as we see the traffic information in the Google Maps. For this, a Google ID has been created for developing the Google Map tracker and the refresh of the animal information will be done by using the Meta tag and jarring effects on the final map outputs. In this process, the base station will be getting the information of the GPS data with longitude, latitude, altitude, speed and time of the animal movements. This data will be converted into decrypt form and dumps the same into MySQL database and updates the same on the Google Maps.

c) Sensor-based Mobile Technology: There is an exponential rise in using smart-phones as a sensing device with all kinds of sensors (such as gyroscope, GPS, temperature, etc.) embedded within mobile phones. The introduction of the internet on mobile technologies made this combination more powerful to make it an emerging tool for various applications and as a real-time tracking tool as well [34]. This technology with a full arsenal of sensors makes this to be used for navigation, location-based services, mobility 
analysis, etc. However, for the current problem, one needs to have a customized device, which is suitable to tag with the animals travelling in extreme weather conditions as well. Some of the sensors existing in the mobile technology may not be very much suitable for extreme heat conditions of Saudi Arabia. Therefore, the selection of the devices and sensors must have a careful look before they are adopted in this problem statement. In the current architecture, the sensors are being used to generate an audio alert for the drivers when the movement of animals found to be communicated by the LoRa Base Station. This audio voice will be loud enough and will be OFF only when the driver sitting in the car press the message acknowledge button.

d) LoRa Wireless RF Technology: This is also known as a LoRaWAN, which is a low power wide area network (LPWAN) grabbing the attention of a large number of people across the globe. This is one of the latest technologies connecting the devices in rural areas and urban areas for up to 30 miles in indoor environments with low energy consumption [35]. The battery life of these devices can be up to 10 years; hence, reducing the battery replacement cost gives an edge for most of the tracking systems. This is one of the GPS-free tracking application, which provides low power benefits as compared to other technologies in the market. This technology can be implemented as the greatest tool for the animal tracking purpose due to the flexibility and adaptability with the devices in motion with low power consumption, reduced cost, minimum infrastructure, battery replacements and low overall operating expenses. It supports mobile technologies, millions of messages and requirements of public network operators to serve huge markets.

The biggest advantage of LoRa lies in its ability to provide efficient, flexible and with the reasonable economic solutions for most of the real-time problems in most of the rural and indoor applications, where most of the cellular and $\mathrm{WiFi}$ networks proved to be ineffective. It is a good choice for long range and Internet of Things (IoT) solutions with low power applications. It also enables different types of tracking applications in the absence of GPS and the LoRaWAN protocol helps to create the interoperability among different applications, IoT devices, and telecommunication operators. The architecture of a LoRaWAN consists of four major sections: a) end nodes, b) concentrator/gateway, c) network server and d) Application server as shown in Fig. 5.

- Functioning and Security of LoRa Architecture

Most of the IoT devices using the LoRa consist of a combination of the sensors with LoRa transceivers at the endpoints. These endpoints are connected in a star network and transmit the signals received from the sensors when they detect the movement of the devices consisting of LoRa sensors. The base station receives the information and passes the same through different gateways using standard IP connections. The data use different types of standard protocols to connect with telecom networks. The network servers manage the data based on the functions to eliminate the duplicated packets. The application servers will control the actions of the endpoints and/or collect data from the endpoints.

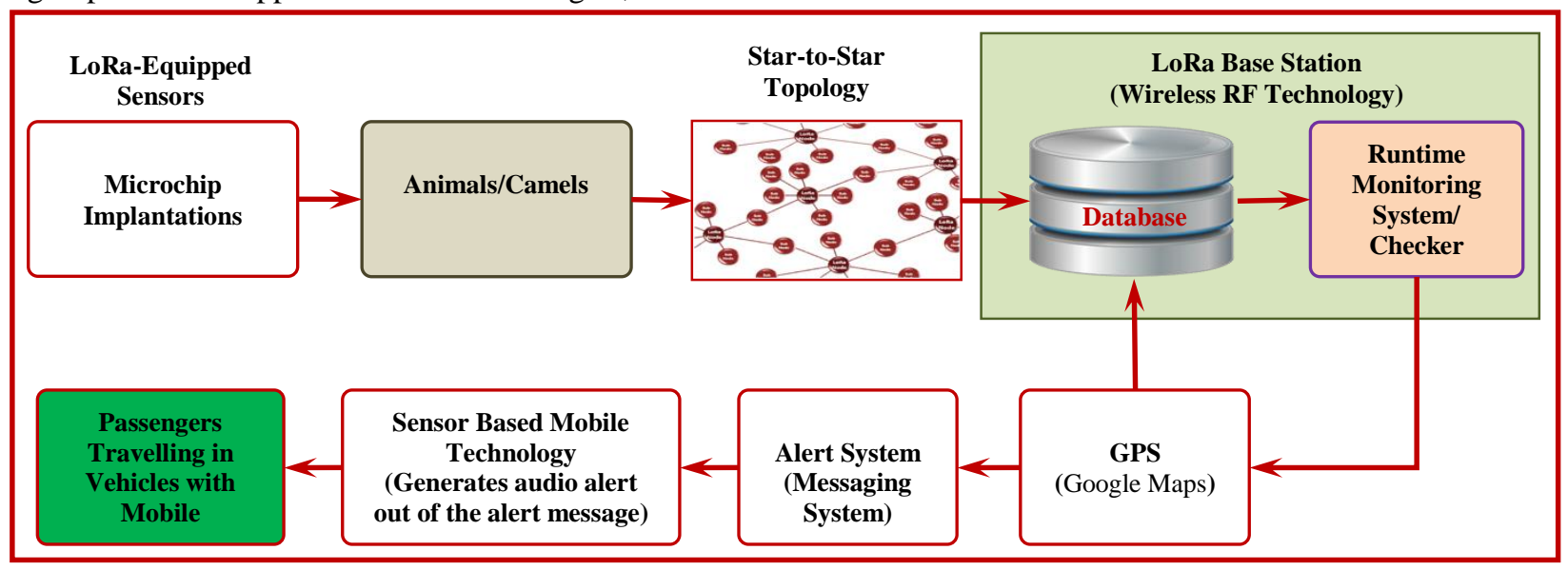

Fig. 4. Shows the Proposed Architecture for Safe Travelling in Saudi Arabia.

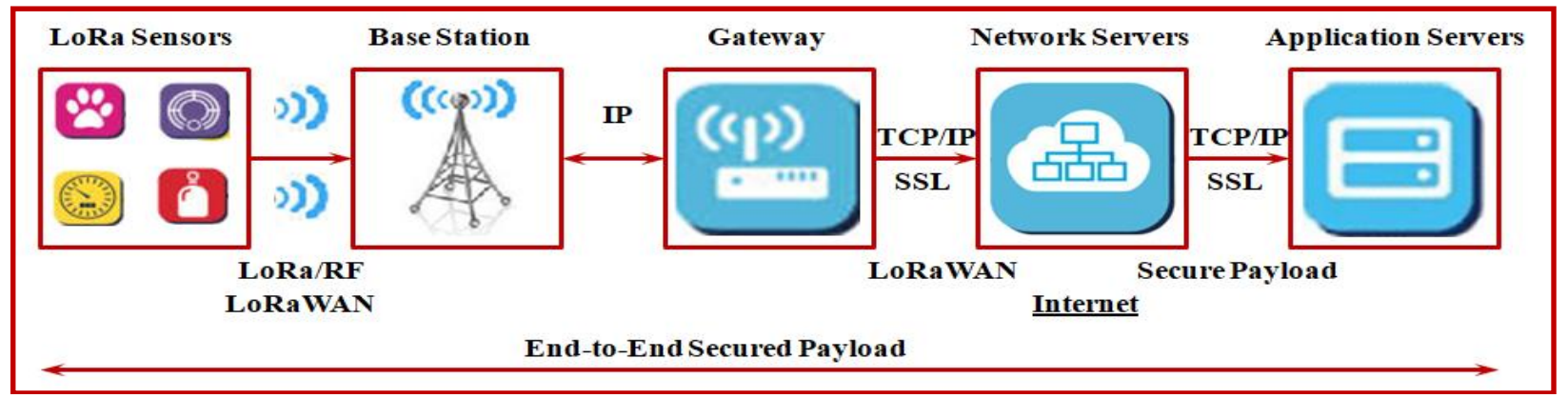

Fig. 5. Shows the LoRaWAN Architecture. 
In the LoRa messaging, the messages are transmitted by using the LoRaWAN network by the end devices, which helps to improve the resilience of the network. Multiple base stations in an area may increase the deployment capital but also helps to enhance the performance. Multiple receptions are filtered at LoRa server, which also helps in providing the security checking. The security on LoRa network is provided by unique network key (EU164) at network levels, unique application key (EU164) at the application level and devicespecific key (EU128) for the device levels.

\section{FunCtioning OF the PROPOSED ARChiteCtuRE}

The following steps will be implemented to monitor the movement of camels on the highways/roads of Saudi Arabia.

a) Installation of LoRa Base Stations to establish the communication between animals and Nodes (sub-nodes too): In this work, the animals are implanted with LoRa sensors into their skin in the first stage. On the other hand star topologybased networks are created with nodes and sub-nodes of specific identification techniques also. Throughout the area, these nodes and sub-nodes are covered using the LoRaWAN. All these nodes and sub-nodes are connected with certain base stations. Such a combination of nodes, sub-nodes and base stations are repeated throughout the highways at different places as a Unit. The nodes will communicate with the base stations when an animal (which is implanted with LoRa sensor) is identified within the different ranges as shown in Fig. 6. The range of a Unit will be between 10-300 $\mathrm{m}$ from the highway divided into three zones: red zone $(0-10 \mathrm{~m})$, yellow zone (10-100 m) and green zone (100-300 m).

b) Establishing communication between the base stations and GPS based mobile phones: The Units are connected with the GPS systems simultaneously giving specific information about each node to update the latitude, longitude, altitude, etc. on a regular basis. Google maps APK is installed with the present application which displays the sensor data received from the animals at different locations.

The runtime monitoring system will check the database for animal movements from the information received from the base stations (see Fig. 7). The Checker component will try to assess the information obtained from the base stations and identify the animal movements in the different zones.

c) Establishing an alert system using the proposed mobile application based on the distance between the animals and main roads: If the animals are within the green zone (i.e. safe zone) means there will not be any kind of alert. But if the animal movement is in the yellow zone (i.e. the possibility of animals rushing on to the highway is more) means there will be an alert to the drivers on their mobile application with a message and caution sound. However, if the animals are moving in the red zone (i.e. indicating a need for serious attention by the drivers) means there will be a message alert and the sensors of the mobile phone will activate a vibration with ring tone to alert the drivers to be more careful and reduce the speed of the vehicle. The sequence diagram with important components and their interaction with different components at different levels in the proposed architecture are shown in Fig. 8.

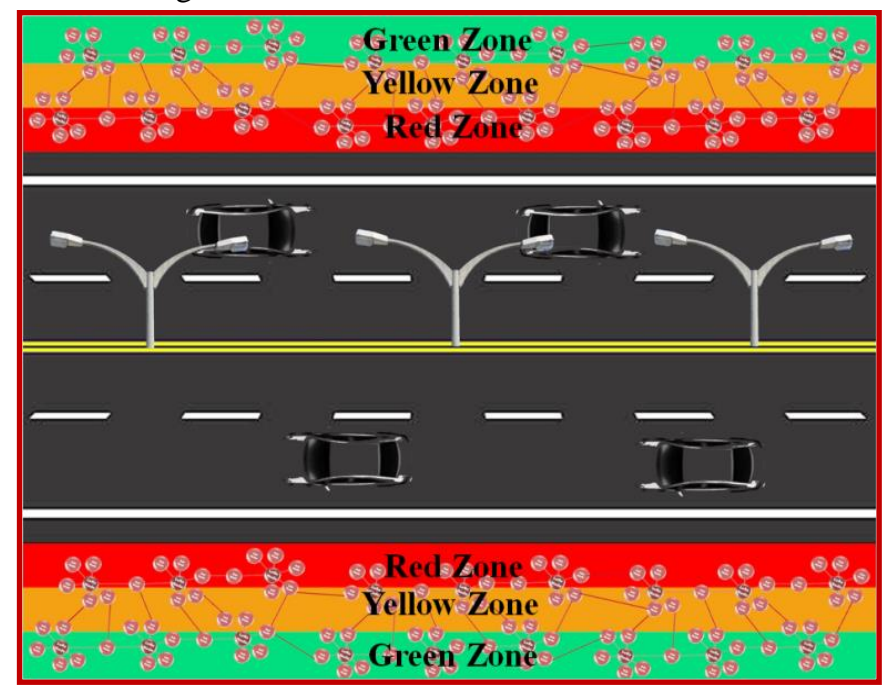

Fig. 6. Defined the different Zones across the Highways for Detecting the Animals with Respect to the Distance between the Road and Animals.

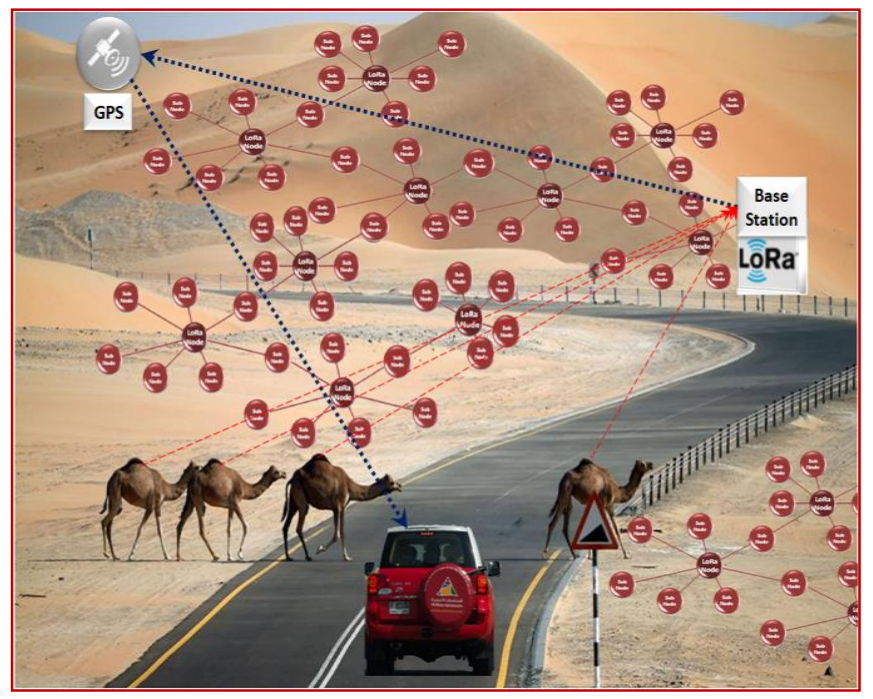

Fig. 7. Shows the Functioning of the Network in the Proposed Architecture. 


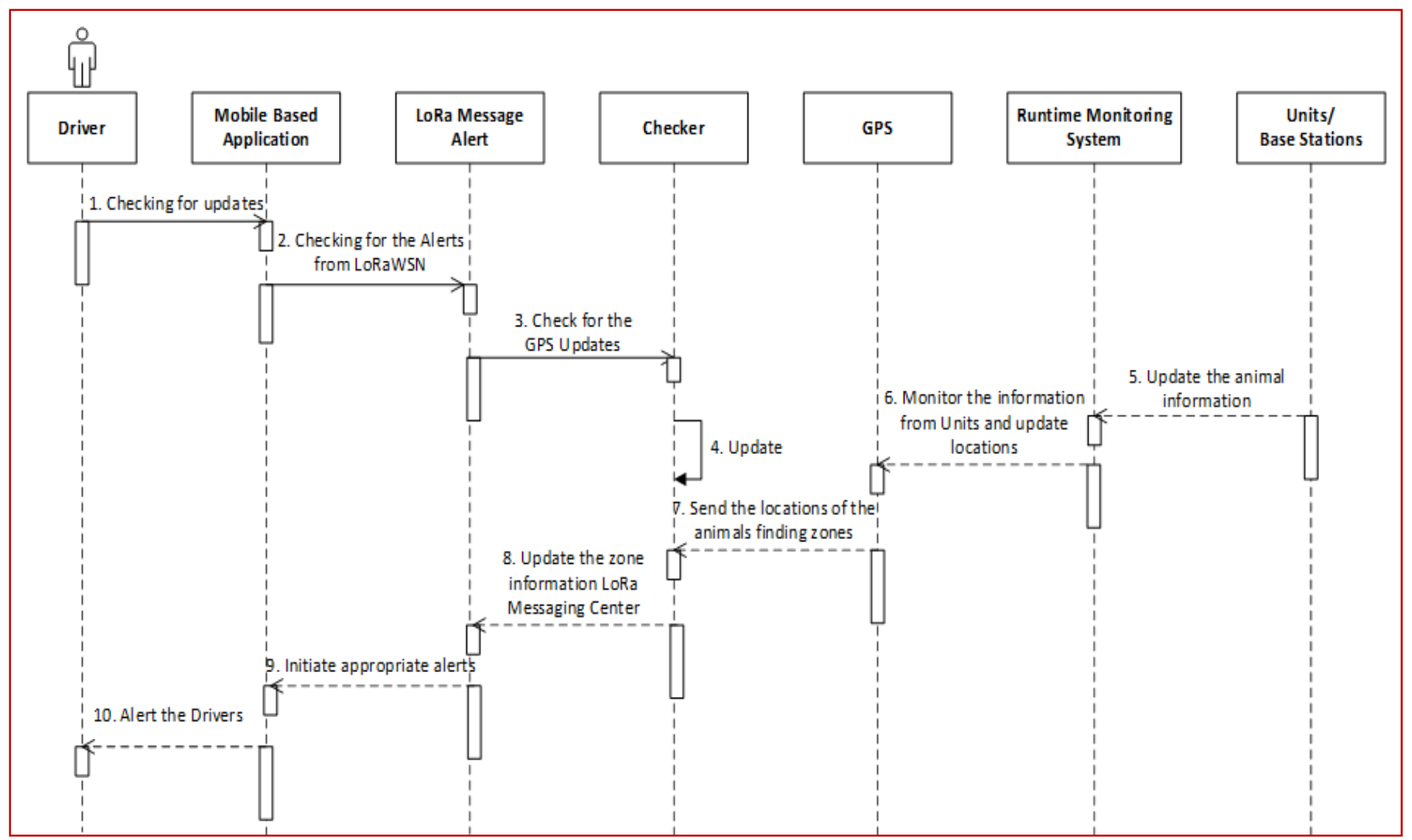

Fig. 8. Shows different Types of Component Interactions using a Sequence Diagram.

\section{CONCLUSIONS}

In the proposed method, the usage of GPS was limited by using LoRaWAN to establish communication between different nodes and sub-nodes after detecting the animals near the highways/roads. The implanted LoRa sensors are capable of working for more than 10-25 years as they are not dependent on any of the external sources. Google Maps platform was used along with the newly developed APK to monitor the sensor data on the mobile for any kind of animal movement near or on the highways. The information of the animal movement will be transmitted to the nearest base stations and the data will be analyzed for false alarms and false negatives in the process in the runtime monitoring system. The location of the nodes detecting the animals will be regularly updated with the GPS system and then based on the checker component analysis the zone wise information will be alerted in the form of LoRaWAN messaging services. The sensor-based mobile applications will be generating the alerts based on the zones as defined in the above discussions. The efficiency of the proposed method revealed satisfactory results by improving the alert quality and response as well. The overall system implementation is very much cheaper as compared with the GPS based systems for the conditions of Saudi Arabia without its own GPS system.

\section{ACKNOWLEDGMENT}

The author would like to thank first the Almighty, Allah for his grace and blessings. The author also thanks his parents, family and teachers for their unconditional support and encouragement throughout the career.

\section{REFERENCES}

[1] S. Al-Ghamdi. "Road accidents in Saudi Arabia: a comparative and analytical study." WIT Transactions on the Built Environment 26 (1970).

[2] T. M. Tamimi, M. Daly, M. A. Bhatty, and A. H. M. Lufti. "Causes and types of road injuries in Asir Province, Saudi Arabia, 19751977: preliminary study." Saudi medical journal 1, no. 5 (1980): 249-256.

[3] M. H. Qayed. "Epidemiology of road traffic accidents in Al-Ahssaa Governorate, Saudi Arabia." (1998).

[4] S. Ansari, F. Akhdar, M. Mandoorah, and K. Moutaery. "Causes and effects of road traffic accidents in Saudi Arabia." Public health 114, no. 1 (2000): 37-39.

[5] S. A. Ansari, M. Mandoorah, M. Abdalrahim, and K. R. Al Moutaery. "Dorsal spine injuries in Saudi Arabia-an unusual cause." Surgical neurology 56, no. 3 (2001): 181-184.

[6] F. M. Abu-Zidan, K. A. Parmar, and S. Rao. "Kangaroo-related motor vehicle collisions." Journal of Trauma and Acute Care Surgery 53, no. 2 (2002): 360-363.

[7] T. P. Pynn, and B. R. Pynn. "Moose and other large animal wildlife vehicle collisions: implications for prevention and emergency care." Journal of Emergency Nursing 30, no. 6 (2004): 542-547.

[8] A. S. Al-Ghamdi, and S. A. AlGadhi. "Warning signs as countermeasures to camel-vehicle collisions in Saudi Arabia." Accident Analysis \& Prevention 36, no. 5 (2004): 749-760.

[9] M. O. Bashir, and F. M. Abu-Zidan. "Motor vehicle collisions with large animals." Saudi medical journal 27, no. 8 (2006): 1116-1120.

[10] M. P. Huijser. Animal-vehicle collision data collection. Vol. 370. Transportation Research Board, 2007.

[11] M. P. Huijser, and A. V. Kociolek. "Wildlife-vehicle collision and crossing mitigation measures: a literature review for Blaine County, Idaho." Western Transportation Institute, Montana State University, Bozeman (2008).

[12] M. P. Huijser, K. J. Paul, and L. Louise. Wildlife-Vehicle Collision and Crossing Mitigation Measures: A Literature Review for Parks Canada, Kootenay National Park. No. 4W1929 A. Western Transportation Institute, College of Engineering, Montana State University, 2008. 
[13] A. Al Shimemeri, and Y. Arabi. "A review of large animal vehicle accidents with special focus on Arabian camels." Journal of Emergency Medicine, Trauma and Acute Care 2012, no. 1 (2012): 21.

[14] M. S. Zahrani, K. Ragab, and A. U. Haque. "Design of gps-based system to avoid camel-vehicle collisions: A." Asian J Appl Sci 4, no. 4 (2011): 362-377.

[15] K. Ragab. "Simulating camel-vehicle accidents avoidance system." International Journal of Future Generation Communication and Networking 4, no. 4 (2011): 43-56.

[16] H. M. Hassan, L. Dimitriou, M. A. Abdel-Aty, and A. S. AlGhamdi. Analysis of Risk Factors Affecting Size and Severity of Traffic Crashes in Riyadh, Saudi Arabia. No. 13-2333. 2013.

[17] R. Al-Awaal. "KSA tops world's mobile phone users." Saudi Gazette (2014).

[18] A. A. Abdo, and A. A. Al-Ojaili. "Assessment of awareness of livestock-vehicle traffic accidents in Dhofar region, Oman." International Journal of, Applied Engineering Research (IJAER) 10, no. 18 (2015): 38955-38959.

[19] E. DeNicola, O. S. Aburizaize, A. Siddique, H. Khwaja, and D. O. Carpenter. "Road traffic injury as a major public health issue in the Kingdom of Saudi Arabia: A Review." Frontiers in public health 4 (2016): 215

[20] M. Khalilikhah and K. Heaslip. "Improvement of the performance of animal crossing warning signs." Journal of safety research 62 (2017): 112.

[21] A. Ward. Lorin. Mule deer behavior in relation to fencing and underpasses on Interstate 80 in Wyoming. No. 859. 1982.

[22] S. M. R. Hosseini, D. Khorasani-Zavareh, and A. Abbasi. "Challenges and strategies for preventing vehicle collisions with camels in South Khorasan Province: a qualitative study." Safety Promotion and Injury Prevention 6, no. 1 (2018): 43-48.

[23] W. Saad, and A. Alsayyari. "Loose Animal-Vehicle Accidents Mitigation: Vision and Challenges." In 2019 International Conference on Innovative Trends in Computer Engineering (ITCE), pp. 359-364. IEEE, 2019

[24] K. K. Knapp. Deer-vehicle crash countermeasure toolbox: a decision and choice resource. Midwest Regional University Transportation Center, Deer-Vehicle Crash Information Clearinghouse, University of Wisconsin-Madison, 2004.

[25] H. Bender. Deterrence of kangaroos from roadways using ultrasonic frequencies-efficacy of the Shu Roo. University of Melbourne, Department of Zoology, 2001.
[26] M. P. Huijser, P. T. McGowen, and W. Camel. Animal vehicle crash mitigation using advanced technology phase I: review, design, and implementation. No. FHWA-OR-TPF-07-01. Western Transportation Institute, 2006.

[27] K. Finkenzeller. RFID handbook: fundamentals and applications in contactless smart cards, radio frequency identification and near-field communication. John Wiley \& Sons, 2010.

[28] M. M. Hurwitz. "Interchangeable attachments for collars, leashes, belts and accessories." U.S. Patent 8,142,053, issued March 27, 2012.

[29] Lighthouse. 2019. 6 Technologies that can be used to track location. [Online] available on URL: <https://blog.lighthouse.io/6-technologiesthat-can-be-used-to-track-location/>, [June 21, 2019].

[30] Y. Grauer. A practical guide to microchip implants. [Online] available on URL: <https://arstechnica.com/features/2018/01/a-practical-guide-tomicrochip-implants/>, [June 23, 2019].

[31] A. Weissbrod, A. Shapiro, G. Vasserman, L. Edry, M. Dayan, A. Yitzhaky, L. Hertzberg, O. Feinerman, and T. Kimchi. "Automated long-term tracking and social behavioural phenotyping of animal colonies within a semi-natural environment." Nature communications 4 (2013): 2018

[32] M. G. T. Mowers. "Tracking device for pets." U.S. Patent 5,850,196, issued December 15, 1998.

[33] P. Bertagna. How does a GPS tracking system work? [Online] available at URL: 〈https://www.eetimes.com/document.asp?doc_id=1278363\#>, [June 25, 2019].

[34] S. Plangi, A. Hadachi, A. Lind, and A. Bensrhair. "Real-Time Vehicles Tracking Based on Mobile Multi-Sensor Fusion." IEEE Sensors Journal 18, no. 24 (2018): 10077-10084.

[35] SEMTECH. What is LoRa? [Online] available at URL: <https://www.semtech.com/lora/what-is-lora>, [June 21, 2019].

\section{AUTHOR'S PROFILE}

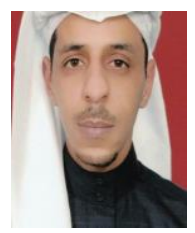

Amr Jadi is an Associate Professor of Software Engineering at Collage of Computer Science and Engineering, University of Hail.

Dr. Jadi received $\mathrm{PhD}$ degrees from De Montfort University and Master's Degree from Bradford University, UK. The author is specialized in with an area interest in Software Engineering, Early warning systems, Risk management and Critical Systems. Presently the author is also involved in various development activities within the University of Hail and abroad as a consultant. 